\title{
Políticas de control de consumo de alcohol, tabaco y otras drogas en América Latina
}

\author{
Peruga, A. \\ Asesor Regional de Alcohol, Tabaco y Drogas. Programa de Salud Mental de la División de Promoción de la Salud. \\ Organización Panamericana de la Salud (OPS/OMS)
}

Enviar correspondencia a:

Armando Peruga. Asesor Regional de Alcohol, Tabaco y Drogas. Programa de Salud Mental de la División de Promoción de la Salud. Organización Panamericana de la Salud (OPS/OMS) 52523 rd St. NW. Washington DC 20037. perugaar@paho.org

\section{RESUMEN}

Se presenta una revisión de la situación de las políticas de control del consumo del alcohol, tabaco y drogas ilegales en América Latina. A pesar de la magnitud de los problemas de salud que genera dicho consumo, los esfuerzos por controlarlo han sido limitados y han tenido un resultado modesto. Es vital la aplicación de políticas decididas por parte de los gobiernos, pero deberán superar ciertos mitos, en especial los que hacen referencia a la contribución a la economía de las industrias que producen y comercializan las drogas legales y abandonar ideologías, que suponen erróneamente que las enfermedades infecciosas son el único problema de salud de América Latina. A la sociedad civil, a través de las organizaciones no gubernamentales, le toca organizar la defensa de los derechos de los ciudadanos afectados directa o indirectamente por el problema, hacer oír su voz y contribuir a la implementación de intervenciones eficaces. Finalmente, la cooperación multilateral y bilateral no está exenta de responsabilidad. En el campo especialmente de las drogas legales, la contribución de la comunidad internacional ha sido insignificante hasta muy recientemente. A la comunidad internacional y sus organizaciones les toca movilizar los recursos necesarios y fomentar políticas apropiadas para controlar el consumo de las drogas legales e ilegales.

Palabras clave: alcohol, tabaco, drogas ilegales, políticas, control, América.

\section{ABSTRACT}

A review is being presented of the control policies on alcohol consumption, and the use of tobacco and illegal drugs in South America. In spite of the magnitude of the health problems generated by such use, the efforts to control them have been limited and have had modest results. The application of definite policies by the governments concerned is vital but they will have to overcome certain myths, particularly those that refer to the contribution made to the economy by the industries that produce and market legal drugs, and abandon ideologies that implicate erroneously infectious diseases are the only health problem in Latin America. And it is up to civil society, through non-governmental organisations, to organise the defence of the rights of inhabitants, directly or indirectly, affected by the problem, to make their voice heard and to contribute to the implementation of effective interventions. Finally, multilateral and bilateral cooperation is not exempt from responsibility. The contribution of the international community has been insignificant until very recently, particularly in the field of legal drugs. It is up to the international community and its organisations to mobilise the necessary resources and to promote the appropriate policies to control the use of legal and illegal drugs.

Key words: alcohol, tobacco, illegal drugs, policies, control, America.
C ontrariamente a lo que se suele pensar, los países menos desarrollados del globo muestran una carga de enfermedad predominantemente atribuible a las enfermedades crónicas no transmisibles y a las lesiones externas. América Latina no es una excepción. En esta región un $80 \%$ de todas las defunciones son atribuibles al conjunto de las ENT y los accidentes ${ }^{1}$. Entre los factores de riesgo que con- tribuyen a la magnitud del problema está el consumo de sustancias que contienen dos drogas legales: la nicotina y el alcohol. Se estima que la proporción de defunciones anuales atribuibles al tabaco y al alcohol en América Latina es de 14 y 15\%, respectivamente 2 . El consumo de otras drogas, como son las ilegales, también es motivo de preocupación, aunque no tanto por la magnitud de la carga de enfermedad que gene- 
ran como por los problemas sociales y de orden público que ocasiona, y las imágenes que dicho consumo evoca en la conciencia colectiva.

A pesar de la magnitud del problema que generan, los esfuerzos por controlar el consumo del alcohol, el tabaco y de las drogas ilegales han sido limitados y han tenido un resultado modesto. En el caso del tabaco, gran parte de los esfuerzos preventivos han ido dirigidos a informar y educar sobres los riesgos de la adicción a la nicotina a los escolares con la esperanza de que no se conviertan en fumadores. Hoy sabemos que los programas escolares tienen un efecto preventivo pasajero, muy limitado o incluso nulo. Tanto es así que la propia Philip Morris ha patrocinado programas escolares en 10 países de la región promocionando la idea de que fumar es una decisión de adultos, en lo que constituye una campaña para lavar su imagen de sin correr absolutamente ningún riesgo de los jóvenes dejen de comenzar a fumar. Mientras, la industria sigue manteniendo una feroz campaña publicitaria para atraer nuevos consumidores a unos precios mucho más asequibles que en los países desarrollados. Y sin embargo, muy pocos países han establecido medidas que realmente funcionan.

Los estudios científicos indican que las tres medidas que más impacto tienen para disminuir la prevalencia del tabaquismo son la prohibición total o casi total de la publicidad, el aumento de los precios del tabaco mediante los impuestos y la protección de los no fumadores mediante la creación ambientes libres de humo ${ }^{3}$. Sólo Brasil y Cuba han establecido medidas para prohibir la publicidad -excepto en los puntos de venta- y el patrocinio de actos deportivos y culturales por parte de la industria. El precio del tabaco ha permanecido muy asequible en todos los países. En el mejor de los casos, los aumentos de los impuestos al tabaco han sido esporádicos y discontinuos, como es el caso de Colombia. En otros casos, como Argentina, se han visto disminuciones de los impuestos sobre el tabaco y en otros, como Costa Rica, el precio real ha disminuido. La mayor parte de los países tienen reglamentada la protección de los no fumadores en los espacios públicos mediante la creación de zonas para fumadores y para no fumadores. Sin embargo, estas divisiones son totalmente inútiles para la protección de los no fumadores, ya que no existen barreras físicas efectivas que dividan ambas zonas. Todavía no se ha comprendido que las zonas compartidas no protegen a los no fumadores ya que incluso la tecnología de ventilación existente más avanzada para crear flujos de aire que permita la evacuación del aire contaminado con el aire del tabaco requeriría fuerzas equivalentes a un huracán para ser efectivas.
En el caso de las bebidas alcohólicas, los esfuerzos han sido hasta ahora sobre todo clínicos, orientados al tratamiento del consumo problemático, aunque la infraestructura y los recursos dedicados a este esfuerzo han sido escasos y dispersos. En el ámbito preventivo, ha habido una respuesta muy tímida a lo que son los principales instrumentos de la industria alcoholera para promover el consumo, sobre todo en los miembros más jóvenes de la sociedad. Precisamente dirigido a este sector del mercado, la industria ha promovido una gran variedad de productos a precios populares y sabores dulces atractivos para los más jóvenes. Aunque esta ha sido una estrategia típica de Europa, se está introduciendo poco a poco en América Latina. Por otra parte, la comercialización de los productos alcohólicos ha tomado un nuevo giro en la última década, pasando de la publicidad directa a actividades promocionales indirectas. Hoy se estima que el $75 \%$ del multimillonario presupuesto publicitario de la industria alcoholera se utiliza en patrocinios de actos culturales y deportivos, concursos llamativos para los más jóvenes, y regalo de productos ${ }^{4}$. En el lenguaje del publicista, estas campañas van dirigidas a crear una relación íntima entre el consumidor y el producto, de manera que este forme parte inseparable del estilo de vida y valores de aquél. Mientras el sector salud dedica sus esfuerzos preventivos principalmente a educar a los escolares sobre los peligros del alcohol o a enseñarles técnicas de resistencia de la presión de sus pares, entre otras cosas. Como en el caso del tabaco, estas intervenciones son ineficaces, como demuestra una reciente revisión de la literatura científica 5 .

Las medidas más efectivas para disminuir el consumo de alcohol incluyen el aumento de los precios y la prohibición de la publicidad. En un reciente estudio, todos los países de la América Latina indicaban tener políticas dirigidas a controlar el consumo de bebidas alcohólicas y sus consecuencias más perniciosas. Sin embargo estas políticas no contemplan aspectos claves. De 16 países de América Latina para los que tenemos información ${ }^{6}$, sólo Brasil tiene aprobada legislación que prohibe la publicidad de los productos alcohólicos. La mayor parte de los demás países tienen regulado el lugar y la hora en donde se puede hacer publicidad -en cuatro países ni siquiera eso-. Aun esta débil legislación no se cumple. Una evaluación reciente de los anuncios sobre el consumo de tabaco y alcohol en la televisión hondureña llegó a la conclusión de que $43 \%$ de los anuncios se transmiten durante los fines de semana a pesar de que la legislación lo prohibe. Honduras también prohibe la transmisión de estos anuncios antes de las 20 horas, aunque 
el estudio determinó que 39\% de estos anuncios se vieron entre las 18 y las 20 horas, el horario preferido de niños y adolescentes. Casi la mitad de todos los anuncios se transmitieron durante los programas orientados a los niños o la familia'.

La respuesta internacional frente al problema de las drogas ilegales ha sido notoria, ya que la comunidad internacional se ha dotado de tres tratados internacionales: la convención única sobre narcóticos de 1961, la convención sobre sustancias psicotrópicas de 1971 y la convención de las Naciones Unidas contra el tráfico ilegal de narcóticos y sustancias psicotrópicas de 1988. Además se ha dotado de una agencia de las Naciones Unidas especialidad en el tema (UNDCP) y la comunidad de países americanos ha creado una comisión especial (CICAD) bajo el paraguas de la Organización de Estados Americanos. Esto ha permitido avances, pero estos se han ceñido fundamentalmente al control de la oferta. Doce países de América Latina tienen Planes Nacionales de Control de Drogas. Estos planes hacen énfasis en el control de la oferta mediante la destrucción de los cultivos, la acción policial sobre el tráfico y la criminalización del consumo. Los resultados de este enfoque han sido limitados hasta ahora. Es necesario hacer hincapié en el control de la demanda, mediante intervenciones de prevención, desintoxicación, tratamiento y rehabilitación, así como de reducción de daños. Para muchos adictos, el tratamiento y la reinserción son las únicas opciones que tienen para salir de la espiral de marginación, violencia y pobreza que crea el comercio y el consumo de las drogas ilegales. Esta es una contribución fundamental del sector salud y pareciera que a ello habrá que dedicar una atención especial en el futuro inmediato.

Esta sucinta revisión de la situación de las políticas de control del consumo del alcohol, tabaco y drogas ilegales deja claro que queda mucho por hacer y que hay poderosos intereses económicos opuestos a los cambios necesarios para crear sociedades más saludables. Ante este panorama, es vital la aplicación de políticas decididas por parte de los gobiernos, el papel de la sociedad civil para expresar las necesidades existentes, y la contribución de la comunidad internacional.

La contribución de los gobiernos es esencial en cuanto generadores y aplicadores de políticas saludables en el campo de las drogas legales e ilegales. A los gobiernos les toca movilizar los recursos y la voluntad para diseñar e implementar las medidas que sabemos que funcionan, pero deberán superar ciertos mitos, en especial los que hacen referencia a la contribución a la economía de las industrias que producen y comercializan las drogas legales. Otro reto que los gobiernos deben afrontar es la modernización de los sistemas de valoración de las necesidades de salud y priorización de respuestas. Estos todavía están anclados en ideologías -como la de la transición epidemiológica- que siguen primando los problemas infecciosos y maternoinfantiles sobre el resto. Sin restar importancia a estos, la realidad es que América Latina vive lo que se ha denominado una polarización epidemiológica, en la que conviven problemas tradicionalmente de los países menos desarrollados con los de los más desarrollados. La realidad está ahí, pero la respuesta apropiada no acaba de llegar.

La cooperación multilateral y bilateral no está exenta de responsabilidad. Los datos existentes indican que la ayuda al desarrollo dedicada por unidad de necesidad a los problemas infecciosos es más de cien veces superior que la dedicada por unidad de necesidad a los problemas como los ocasionados por las drogas legales e ilegales ${ }^{8}$. En este campo, especialmente en el de las drogas legales, la contribución de la comunidad internacional ha sido insignificante. Notoriamente ausente de las resoluciones de la Organización Mundial de la Salud, incluida la Organización Panamericana de la Salud está el tema de las políticas efectivas para controlar el daño ocasionado por el consumo de bebidas alcohólicas. A la comunidad internacional y sus organizaciones les toca movilizar los recursos necesarios y fomentar políticas apropiadas para controlar el consumo de las drogas legales e ilegales.

Finalmente, a la sociedad civil, a través de las organizaciones no gubernamentales, le toca organizar la defensa de los derechos de los ciudadanos afectados directa o indirectamente por el problema, hacer oír su voz y contribuir a la implementación de intervenciones eficaces. No se puede imaginar la solución de los problemas creados por el consumo de drogas legales e ilegales sin la participación activa de la sociedad afectada y si el apoyo generoso de gobiernos y organizaciones internacionales a organizaciones no gubernamentales profesionalizadas y responsables públicamente de los recursos que se depositen en sus manos. La reciente creación de la RIOD (Red Iberoamericana de ONGs que trabajan en Drogodependencias) ${ }^{9}$ es un paso adelante. Pero serán necesarios muchos más.

\section{BIBLIOGRAFÍA}

(1) Escobar MC, Petrásovits A, Peruga A, et al. Mitos sobre la prevención y el control de las enfermedades no transmisibles en América Latina. Salud Pública de México 2000; 42(1)56-64. 
(2) Organización Panamericana de la Salud. La Salud en las Américas 2002. En prensa.

(3) Banco Mundial. La epidemia del tabaquismo: los gobiernos y los aspectos económicos del control del tabaco. Organización Panamericana de la Salud. Publicación científica 577. Washington DC, 2000.

(4) World Health Organization. Global Status Report: Alcohol and Young People. WHO/MSD/MSB/01.1. WHO Geneva, 2001.

(5) Foxcroft D. Preventive programs for young people: what works? Invited paper presented at the WHO European
Ministerial Conference on Young People and Alcohol. Stockholm 19-21 February 2001

(6) World Health Organization. Global Status Report on Alcohol. WHO/HSC/SAB/99.11. WHO Geneva, 1999.

(7) Documento del IHADFA, 2000.

(8) Michaud C, Murray CJL. External assistance to the health sector in developing countries: a detailed analysis 19721990. Bull. World Health Organ. 1994; 72:639-651.

(9) Catalá T RIOD (Red Iberoamericana de ONGs que trabajan en Drogodependencias) Adicciones, vol 13, 2, 127-130. 